It might be added that before use the cement stoppers were boiled in distilled water for 6 hours. The use of cement stoppers is not restricted to an apparatus like the above, but could be extended to other forms where rubber or cork is objectionable.

The accompanying figure will illustrate the apparatus. A, adjustable water supply; $\mathrm{B}$, cement stoppers; C, automatic adapter. HAL, W. MOSELEY, ROLLIN G. MYERS.

RICHARDSON ChEMICAI, IABORATORY,

TUlaNe UNIVERSTY, NEW ORLEANS, LA.

A Fractional Distillation Tube.-A fractional distillation tube can be made by fastening together Kjeldahl connecting bulb tubes by means of rubber tubing as shown. A bent glass tube can be substituted for the fractional distillation tube connected to the uppermost bulb.

W. G. Friedemann.

Orzagoma Agricultural Experiment Station, Strllwater, OKLA.

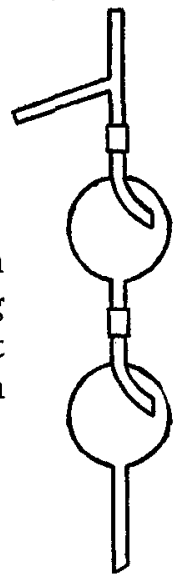

Fig. I.

[CONTRIBUtion FROM THE CHEMICAL LABORATORY OF THE DAKOTA WESLEYAN UNIVERSITY.]

\title{
THE PREPARATION OF METHYLAMINE.
}

By HILTON IRA JONES AND RUTE WheatleEY.

Received May 27, 1918.

During a research on the commercial synthesis of adrenalin in 1907I 908 , one of us had occasion to require large quantities of methylamine. We could not buy and were therefore forced to make what we needed. We at that time tried out all the methods we could find described in the literature for the production of methylamine, and found that described by Brochet and Cambier ${ }^{1}$ was easily the best.

For some two years past we have been engaged in a study of certain organic reactions in which a gas is evolved. Among some score of reactions studied has been this old one we formerly used for methylamine. We had intended to submit our results altogether in a paper on "The Effects of Reduced Pressure on those Organic Reactions in which a Gas is Evolved " but the recent appearance of an article by Werner ${ }^{2}$ has made us resolve to publish these results separate from the rest of the forthcoming series.

Since organic reactions are not ordinarily ionic, the direction they take must be determined by the relative concentrations of the reacting factors, many of which are no doubt the result of alkylidene dissociation of

${ }_{1}$ Bull. soc. chim., I3, III, 392 (1895).

2 J. Chem. Soc., II, 844 (I917). 
the sort so frequently pointed out by Nef. In case of reactions in which a gas is evolved we have found that the pressure exerts a very great influence upon the concentration of those products which decompose into the gas, and of course, the lowered pressure lowers the temperature at which the reaction proceeds. The recent studies made in the University of Illinois upon the effects of pressures upon organic reactions showed clearly the small part which pressure alone plays in most of these reactions, but they were not reactions of the type that we are studying.

Werner, in his excellent article, gives the best explanation of the mechanism of this reaction for the preparation of methylamine that has yet appeared and is right in stating that Knudsen ${ }^{1}$ apparently had little conception of the steps involved. The primary reaction between formaldehyde and ammonium chloride undoubtedly runs as follows:

$$
2 \mathrm{HCHO}+\mathrm{NH}_{4} \mathrm{Cl}=\mathrm{CH}_{3} \mathrm{NH}_{3} \mathrm{Cl}+\mathrm{HCOOH}
$$

The formic acid thus produced is partly changed to methyl formate and to a small extent to methylal, but most of it is oxidized to carbon dioxide and water.

If the heating be too prolonged or at too high a temperature, the yield of the monomethylamine is decreased and the production of dimethylamine is increased, even some trimethylamine being formed. Werner explains these known facts by means of the following equations, in which some of the intermediate bodies are hypothetical. Yet his explanation is, we believe, the best that has ever been advanced.

$$
\begin{aligned}
& \mathrm{HCHO}+\mathrm{NH}_{3} \mathrm{HCl}=\mathrm{HCH}\left\langle\mathrm{NH}_{2}=\mathrm{CH}_{2} \mathrm{NH}(\mathrm{HCl})+\mathrm{H}_{2} \mathrm{O} .\right. \\
& \mathrm{CH}_{2} \mathrm{NH}(\mathrm{HCl})+\mathrm{H}_{2} \mathrm{O}+\mathrm{HCHO}=\mathrm{CH}_{3} \mathrm{NH}_{2} \mathrm{HCl}+\mathrm{HCOOH} . \\
& \mathrm{HCHO}+\mathrm{CH}_{3} \mathrm{NH}_{2} \mathrm{HCl}=\mathrm{CH}_{2}: \mathrm{N} \cdot \mathrm{CH}_{3} \mathrm{HCl}+\mathrm{H}_{2} \mathrm{O} \text {. } \\
& \mathrm{CH}_{2}: \mathrm{N} \cdot \mathrm{CH}_{3} \mathrm{HCl}+\mathrm{H}_{2} \mathrm{O}+\mathrm{HCHO}=\left(\mathrm{CH}_{3}\right)_{2} \mathrm{NH} \cdot \mathrm{HCl}+\mathrm{HCOOH} \text {. (4) } \\
& \mathrm{HCHO}+{ }_{2}\left(\mathrm{CH}_{3}\right)_{2} \mathrm{NH} . \mathrm{HCl}=\mathrm{CH}_{2} \bigcup_{\mathrm{N}\left(\mathrm{CH}_{3}\right)_{2}}^{\mathrm{N}\left(\mathrm{CH}_{3}\right)_{2}}{ }_{2} \mathrm{HCl}+\mathrm{H}_{2} \mathrm{O} \text {. } \\
& \mathrm{CH}_{2}\left\langle\begin{array}{l}
\mathrm{N}\left(\mathrm{CH}_{3}\right)_{2} \\
{ }_{\mathrm{N}}\left(\mathrm{CH}_{3}\right)_{2}
\end{array}\right.
\end{aligned}
$$

A study of these equations of Werner's makes it plain that if we could hold down the temperature and at the same time hasten the decomposition of the formic acid as it is formed, that we could in this way pull the equilibrium to the right in the first case, Equations I and 2, and thus get the monomethylamine as almost the sole product, this being the valuable thing and the one that we are after. Four of our experiments

s Ber., 47, 2694 (I9I5). 
performed first nearly two years ago show the correctness of these conclusions.

\section{Experimental.}

Four experiments were carried out, the first duplicating the one by Werner; the second was a slow distillation like the first, except that it was conducted in a vacuum; in the third the material was refluxed at ordinary pressure for 8 hours before the distillation, which was also at ordinary pressure; in the fourth the material was refluxed for 4.5 hours in a vacuum before the distillation, which was also in a vacuum.

One hundred and fifty g. of ammonium chloride and $300 \mathrm{~g}$. of $40 \%$ formaline solution were slowly warmed together and soon a rapid evolution of carbon dioxide began. The mass was slowly distilled, using a long, well-cooled coil condenser, the receiver also being kept cold. The distillation took 4.5 hours, the temperature never being allowed to rise above $105^{\circ}$. The distillate weighed $74.5 \mathrm{~g}$., and the residue $349.5 \mathrm{~g}$. The loss of $26 \mathrm{~g}$. being due chiefly to evolution of carbon dioxide.

The distillate had a specific gravity of 0.947 and was strongly acid. $[\alpha]_{\mathrm{D}}^{15}=\mathrm{I} .453$. Five cc. was taken and digested with $50 \mathrm{cc} .0 .5 \mathrm{~N} \mathrm{NaOH}$. After digestion there were required $22.7 \mathrm{cc}$. $0.5 \mathrm{~N} \mathrm{HCl}$ for neutralization. Five cc. was heated on a water bath until all the methyl formate and methylal were evaporated off and the acid residue required $3.2 \mathrm{cc}$. for neutralization. This gives us a fairly accurate measure of the amounts of free acid and methyl formate present. Considerable amounts of methylal seem to be always formed but no attempt was made to determine the exact percentage of this.

As soon as the residue from the distillation was cold the ammonium chloride which had crystallized out was filtered off with suction and the filtrate further concentrated by evaporation and again cooled, a second crop of ammonium chloride being obtained. As Werner has pointed out, the ammonium chloride is quite insoluble in the strong solution of the methylamine hydrochloride and consequently there is no trouble in having the separation very sharp. The crystal forms of the two hydrochlorides are so different that it is easy to see if either one is contaminated with the other and if so, this can be corrected by appropriate concentration or dilution. The total weight of the ammonium chloride from (I) was $46.47 \mathrm{~g}$. The filtrate from the ammonium chloride was evaporated until crystals began to form at the edge and set aside to cool, and the first crop of methylamine hydrochloride was filtered off. Further evaporation gave additional crops. In all 4 crops were obtained which, when freed from dimethylamine, weighed $70.67 \mathrm{~g}$. The combined chloroform extractions of these crops gave $12.4 \mathrm{~g}$. of dimethylamine hydrochloride. A residue weighing $43.53 \mathrm{~g}$. remained, which would not crystallize and which we did not attempt to work up as it seemed to have no practical 
value. We note Werner has attempted to resolve the residue without any great success. We have again checked over our results obtained long before Werner's article came out and find close agreement with the results he obtained, though, of conrse, he worked with different purpose and always at ordinary pressures.

In Expt. 2 the same proportions of formaline and ammonium chloride were taken as before and except that the distillation was carried out at a pressure of $20 \mathrm{~mm}$. and consumed only 2.5 hours, the procedure was the same as in No. I.

In Expt. 3, the same proportions were taken and procedure followed as with the others, except that the reaction product was heated to $105^{\circ}$ for 8 hours, using a triple-ball condenser. The heating was stopped as soon as no more carbon dioxide was given off, as shown by testing with barium hydroxide solution. 'The distillation consumed 5 hours.

In Expt. 4 the procedure differed only in that the reaction was refluxed at $20 \mathrm{~mm}$. pressure for 4 hours, or until no more carbon dioxide was given off. The reaction product was then distilled in a vacuum as before, 2 hours being consumed in the distillation.

The following tabulation shows the results of the 4 experiments: TABLE I.--EXPERIMENTAL RESULTS.

Expt. No.

Wt. of distillate, $g \ldots \ldots \ldots \ldots \ldots \ldots \ldots \ldots . \ldots \ldots$

Wt. of residue, g. . . . . . . . . . . . . 349.5

Loss $\mathrm{CO}_{2}, \mathrm{~g} \ldots \ldots \ldots \ldots \ldots \ldots \ldots \ldots . \ldots \ldots$

Sp. gr. distillate

Rotation of distillate.

$0.5 N \mathrm{HCl}$ to neutralize after digestion (see

description), cc................

$0.5 \mathrm{~N} \mathrm{HCl}$ to neutralize after heating, cc. .

Wt. $\mathrm{NH}_{4} \mathrm{Cl}$ remaining, $\mathrm{g}$.

Wt. of $\mathrm{CH}_{3} \mathrm{NH}_{3} \mathrm{Cl}, \mathrm{g} \ldots$

Wt. of $\left(\mathrm{CH}_{3}\right)_{2} \mathrm{NH}_{2} \mathrm{Cl}, \mathrm{g}$.

Wt. of residue not crystallizing, $\mathrm{g}$.
1.

2.

I 17.72

291.0

48.28

0.947

I. 453

I . 040

2.942

$22 \cdot 7$
3.2

34.9

14.8

46.47

70.67

12.40

$45 \cdot 53$
79.9

44.83

9.66

$23 \cdot 53$
3.

4.

$\begin{array}{cc}27.3 & 37.31 \\ 354.5 & 326.0 \\ 68.2 & 92.7 \\ 1.002 & 1.035 \\ 1.731 & 1.106\end{array}$

This tabulation of results brings out several facts clearly:

I. The vacuum refluxing and distillation plainly decreases the amount of ammonium chloride left unused, lowers the temperature and therefore decreases the yield of dimethylamine and other higher methylated bodies, which agrees with Werner's theory, and it increases the acidity of the distillate, the loss of carbon dioxide and the weight of methylamine produced.

2. The vacuum distillation, merely by removing the volatile products as well as the carbon dioxide, causes a marked increase in the weight of the distillate and the amount of the ammonium chloride remaining unchanged, it causes the formation of the lowest percentage of dimethylamine, but also lowers markedly the amount of monomethylamine formed, and it causes 
a higher percentage of esterification and gives a distillate of the highest rotatory power.

3. The long refluxing at ordinary pressure and relatively high temperature gives the smallest percentage of distillate, the highest percentage of non-distillable residue, the highest percentage of esterification, uses up a large amount of ammonium chloride, and gives of course the highest degree of methylation, which means the highest percentage of dimethyl and other higher methylated derivatives, most of which will not crystallize.

4. The theory advanced by Werner to explain this reaction is the first and only correct one, all the observed facts, many of which he did not have, being in accord with his theory.

5. The 4 types of reaction agree with the principles of a larger theory, which applies to all organic reactions of this type in which a gas is evolved. This theory we are working out in a score of other cases.

6. Monomethylamine, a valuable reagent and the member of the series most often desired, is best made by the vacuum reflux method.

MITCEELL, S. D.

[CONTRIBUTiON FRON THE SCHOOL OF ChEMISTRy, University OF PitTsburgh.]

\section{PHTHALIC ACID DERIVATIVES: CONSTITUTION AND COLOR, XIV. ${ }^{1}$ SOME DERIVATIVES OF TETRA- BROMOPHTHALIMIDE.}

By David S. PRatt and Charles O. Young.

Received June 13, 1918.

Tetrabromophthalic anhydride has been prepared by the method previously described for the tetraiodo derivative. ${ }^{2}$ From the resulting product a fairly comprehensive series of compounds related to the corresponding phthalimid has been made, by condensing the anhydride with various primary amines. These will be utilized at some future time in a study of their absorption spectra.

The tetrabromophthalimides follow closely in their general properties the tertachloro- and tetraiodo-analogues, with the differences that might be expected from the substitution of bromine for chlorine or iodine. The bromine derivatives show, to the eye, slightly more of a tendency toward yellow than the tetrachloro compounds, but less so than those containing iodine in the molecule. Similarly in the property of forming unstable, molecular addition products with various solvents and with tertiary amines, the brominated derivatives occupy a position intermediate between the compounds containing chlorine and those containing iodine. Whereas, tetraiodophthalic anhydride and its anils generally gave merely a slight color with dimethyl aniline, tetrabromophthalic anhydride separa-

1 This Journal, 40, I98 (1918).

I'Ibid., 40, 254 (1018). 